\title{
Simulation and Economic analysis of an AGV system as a mean of transport of warehouse waste in an automotive OEM*
}

\author{
Tomé Silva, Luis S. Dias, M. Lopes Nunes, Guilherme Pereira, Paulo Sampaio, José A. Oliveira and \\ Paulo Martins
}

\begin{abstract}
Companies with high quality production systems like the automotive industry OEM's (Original Equipment Manufacturer), need to control the containers in which the raw materials are delivered onto the production lines to make sure quality standards are not breached. They commonly have to change the containers from their suppliers to special clean vessels. Hence a new flow of residues is created by this repacking process, the problem arises with the need to minimize the impact that this flow has on the milk runs that supply the lines with raw materials and maintaining the cost of its operation as low as possible. Different AGV (Automated Guided Vehicles) system configurations were tested based on their financial and functionality feasibility to see if the use of AGVs is viable to perform this kind of activities. SIMIO simulation tool was used to assess the performance of each AGV configuration on the metrics of buffer size, total travelled distances, resource utilization and effect on the output of the plant for four different production levels (units/shift). A configuration was clearly better, for the highest production level scenario: it freed $12 \mathrm{~m} 2$ of buffer area; it reduced operators travelled distances by $88 \%$; it was suitable for $120 \%$ of the current production levels; had a payback time of less than 2 years and a net present value of $232 \mathrm{~K} €$.
\end{abstract}

Keywords: SIMIO; AGVs; Simulation

\section{INTRODUCTION}

This paper focuses on a real problem that an OEM of the automotive sector faced when trying to deal with the congestion between the flow of materials and the flow of waste produced by a repacking process. The waste produced is mainly cardboard and various forms of plastics namely polystyrenes and pet film. The selection of the right material handling system (MHS) is a crucial decision and should be such that allows for future changes to the system, being thus flexible and more importantly compatible with transport methods already in use [1].

In the study the AGV technology was assessed as a conceivable replacement for a manually operated forklift that currently moves the residues from the repacking stations to a treatment facility outside the plant. AGVs have been attracting the attention of the manufacturing industry due to the benefits in the fields of cost reduction, the rapid payback

* Research co supported by COMPETE: POCI-01-0145-FEDER-007043 and FCT - Fundação para a Ciência e Tecnologia within the Project Scope: UID/CEC/00319/2013 and by the Portugal Incentive System for Research and Technological Development, SI I\&DT project in joint-promotion $\mathrm{n}^{\circ}$ 36265/2013 (HMIEXCEL - 2013-2015 Project).

Authors are with the Industrial Engineering Department, School of Engineering, University of Minho, Portugal (e-mails: tome_andrade_silva @hotmail.com; \{1sd, lnunes, gui, zan, paulosampaio, pmartins\} @dps.uminho.pt). They are affiliated to the ALGORITMI Research Centre. time on the investment, especially in multiple shift operations, the increase on efficiency and reliability of operations, and safer industrial environments [2][7][8]. Furthermore AGVs commonly have a good performance when the patterns of movement are repetitive [3][10], which is the case of this project and the reason why this study followed through. The AGVs were not the only solution considered by the company, that had done a previous study on the implementation of an overhead conveyor system, but due to the infrastructural changes needed and the inflexibility of the solution, the idea was quickly abandoned.

There are plenty of design problems associated with installation of AGV systems, most of them being addressed by operational research methods. Some of the most common problems are AGV fleet sizing and flow path design [4][5][11]. Our approach will be different; in our case we want to test how different AGV configurations will perform under various production levels. We already have the flow paths, which can be used, and our pick-up and drop-off locations are already defined. Regarding the flow paths and the location of drop-off and pickup points, we have two options: either we use the repacking stations as pick-up and drop-off locations or we have a central buffer that will serve the same purpose. If we choose the latter then operators will have to dispatch filled bags from the repacking stations to the buffer, and empty bags from the buffer to the repacking stations. So the problem we have is not an optimization effort, because we could not change the layout of the warehouse to optimize the performance of the waste movement system, the warehouse is already defined to increase the performance of the flow of materials, which is the priority of the company. Also the overall performance of a system will be considered as the result of the conjugation of various metrics: travelled distances, resource utilization, the entropy that this system will induce on the milk runs that supply the production lines, space utilization, and cost of operation and implementation.

Now, to determine the number of AGV's an analytical model would be a feasible option, but the number of AGV's determined would not take into account, that the AGV's will eventually share portions of the flow-paths with 6 manual operated milk runs, meaning that the milk runs will have priority in the approach of junctions and the AGV's will have to wait, for this reason the number of AGV's calculated through this method may not be trustworthy. Hence, and because we are already using simulation for the other design problems, we'll also use it to determine the number of AGV's needed.

This simulation project will be divided in the following steps: (1) input data collection; (2) Construction of the 
simulation models; (3) Model validation (4) Running of experiments; (5) Results interpretation.

The paper is organized in following manner: firstly the problem will be described; secondly, all the simulation steps presented will be addressed, and lastly the results of the experiments will be interpreted and conclusions will be drawn.

\section{PROBLEM DESCRIPTION}

Currently there are 4 main areas where residues are generated: the repacking zone with 5 repacking stations; a supermarket of raw materials, located on the floor above; the final assembly region; and the unloading docks and the checking stations, where materials are received and deliveries checked (Figure 4). Presently, there are 4 resources per shift involved in the movement of waste.

Two operators move bags from the assembly area, repacking stations, and supermarket to a buffer where these filled bags wait for a manually operated forklift to move them to a waste treatment facility outside the plant. The forklift gathers the bags from the buffer, unloading docks, and delivery area. The buffer serves and storages waste from the supermarket, repacking stations and final assembly. In the case of the checking stations and the unloading docks the forklift collects the garbage directly at source of its creation. After the collection of the packed bags, the forklift should delivery empty receptacles to the buffer, checking stations and unloading docks. Upon the delivery of empty bags to the buffer, the two operators in charge of the zones served by it should transport those bags to the stations where they are being needed.

The problem with this method is that it consumes a lot of resources on a non-value added process and creates entropy on the flow of raw materials being transferred between the repacking stations and the production lines. In addition, the flow paths of the milk runs and the waste movement process have a coincident junction. The fact that the buffer is precisely located at this point and that the forklift does Uturns on this exact same location aggravates the congestion between the flows. On the event of an approach from one of the milk runs while the forklift is maneuvering in the junction, it has no option but to stand by, waiting for the path to be freed. With this project we aim to achieve a reduction of the operational costs of the waste movement system without increasing the congestion between flows, proving or disproving the AGV as a possible solution

\section{Simulation}

\section{A. Data collection}

The data collected consisted of:

- Forklift speeds;

- Operators walking speeds;

- Waste generation rate at each of the areas of the study;

- Number of trips done from each of the areas to the treatment facility by the forklift and number of bags transported in each trip;
Figure 1 shows the quantity of residues that were produced on each of the zones being studied. It was no surprise to see that the repacking stations contributed with the largest share of waste production. But the fact that there were peaks and a valley on the waste generation rate was not common knowledge, the explanation comes from the fact that operators have their half hour lunch break around 11:00 AM, and to compensate for this, in the hours that follow, they work at a higher pace in order to pick up with the demand of materials from the assembly lines.

Number of bags filled/hour (average quantities)

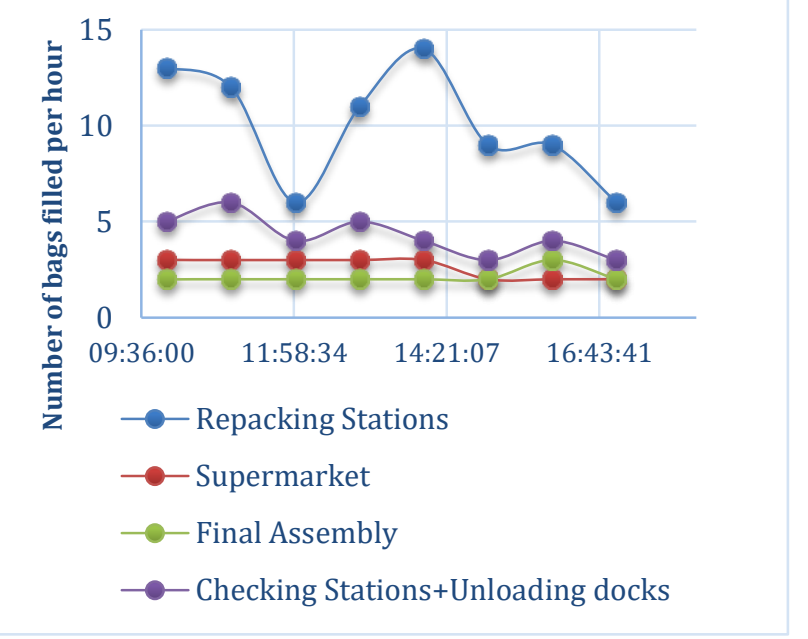

Figure 1-Number of bags Filled/hour

Crossing the waste generation information with the output of the plant (units produced), we found that there is a linear relation between these two variables (Figure 3 ). This is a very important relation that gives us information on how the output of the plant is affected. At the end of a shift the difference between the number of bags filled and the number of bags transported translates itself in losses in the output of the plant. Every time a repacking station has to wait for an empty bag to continue its operation, there will be delays on the deliveries to the production lines and consequently losses on production. The existence of this relation will also make possible to test how the performance of our AGV systems will stand against hypothetical increases on the output of the factory, as we now know how an increase in production can affect the number of bags filled.

\section{B. Construction of the simulation models}

For the construction of simulation models the Simio simulation tool was used [6][9]. Our approach towards simulation was the following: first we constructed the model replicating the currently used system, and then we validated the model comparing its behavior with that of the real system. We checked how the results of the simulation confronted with those of the data collection phase, namely number of trips done by the forklift, and the number of bags filled per shift [12].

To correctly replicate the waste movement system being used, some approximations had to be done. The driver of the forklift had no pick up or drop-off schedules, meaning that he is the one who decides when and where to do a pick-up or 
drop-off. This random behavior was settled in the logic explained in Figure 2.

Each time a filled bag was put into the buffer or was filled at the checking stations or unloading docks, a movement order was generated. Each movement order has the potential to generate a real movement from the forklift, if more than one movement order exist at a specific time, the FIFO rule prevails. When the entity that requires this movement is an empty bag the forklift has to immediately collect all the empty bags waiting to be moved at the treatment facility and take them to their drop-off points. This guarantees that every time the forklift drops-off filled bags into the treatment facility, and if empty vessels are already available in this location (treatment facility), than the next trip has to mandatorily be to take this empty vessels to the locations where the previous filled bags were collected from.

When the entity that requests the movement is a filled bag, a random number is generated according to a uniform distribution with parameters $[1,4]$, if the number that results of this random generation is lower than the actual number of filled bags waiting on the buffer, the movement request will materialize into a real trip. Otherwise the forklift will hold on for the next movement request and wait until the condition is met. This simulates the random behavior of the operator that drives the forklift.

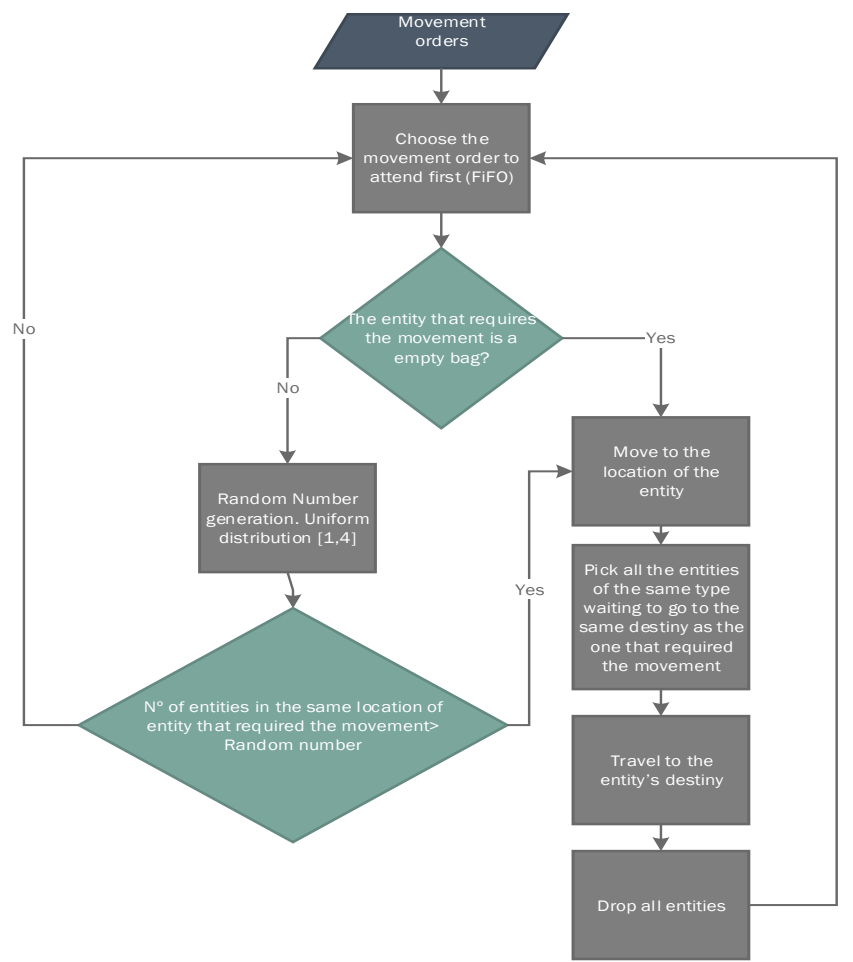

Figure 2- Movement order selection by the transporter (forklift)

\section{Model validation}

To validate the model that replicates the current system we will compare the results drawn from the simulation to the data collected in section 3 . This method assumes that the real data obtained is representative of the behavior of the system, which there is no way to guarantee with $100 \%$ safety. The data collected represents a month of operation, which was the time the company made available for information gathering.
The first variable assessed was the number of filled bags. Note that the simulation results were drawn with a $95 \%$ level of confidence.

\section{№ Bags filled Vs Produced Units}

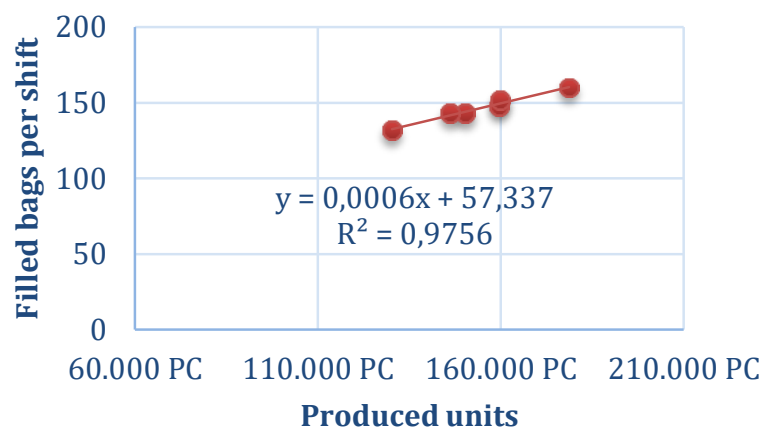

- Series1 Linear (Series1)

Figure 3 - No. of Bags filled vs Produced Units

Table 1-Number of bags filled: Real system VS Simulation

\begin{tabular}{|ccc|}
\hline $\begin{array}{c}\text { Average of observed } \\
\text { data } \\
\text { Bags/shift } \\
152\end{array}$ & $\begin{array}{c}\text { Simulation Results } \\
\text { Bags/Shift }\end{array}$ & Half Width \\
\hline
\end{tabular}

Table 2 - No. of forklift trips: Real system VS Simulation

\begin{tabular}{|c|c|c|c|}
\hline \multicolumn{4}{|c|}{$\mathbf{N}^{0}$ Trips/Shift } \\
\hline & $\begin{array}{c}\text { Average of } \\
\text { observed } \\
\text { data }\end{array}$ & $\begin{array}{c}\text { Simulation } \\
\text { Results }\end{array}$ & Half Width \\
\hline Buffer & 39 & 38,7753 & 0,1542 \\
\hline $\begin{array}{l}\text { Checking } \\
\text { stations plus } \\
\text { unloading } \\
\text { docks }\end{array}$ & 9,875 & 11,5665 & 0,2616 \\
\hline
\end{tabular}

We expected very close values for the number of bags filled because the data inputted in the model was the data collected during the information-gathering phase. Unexpectedly the number of trips done in the simulation was very close to the ones observed in the real system. This means that the approximation done in section $\mathrm{B}$, with the intent of simulating the behavior of the forklift operator, serves that purpose well enough. Empirically this is close enough, although the observed data is slightly out of the Simulation Half Width, for the confidence level of 95\%. The validation process could have been deeper in order to explain those differences or else assuming a difference confidence level. One possible source of this difference is the use o historical data for entities sources and stochastic values for the forklift behavior, namely the time of movements. 


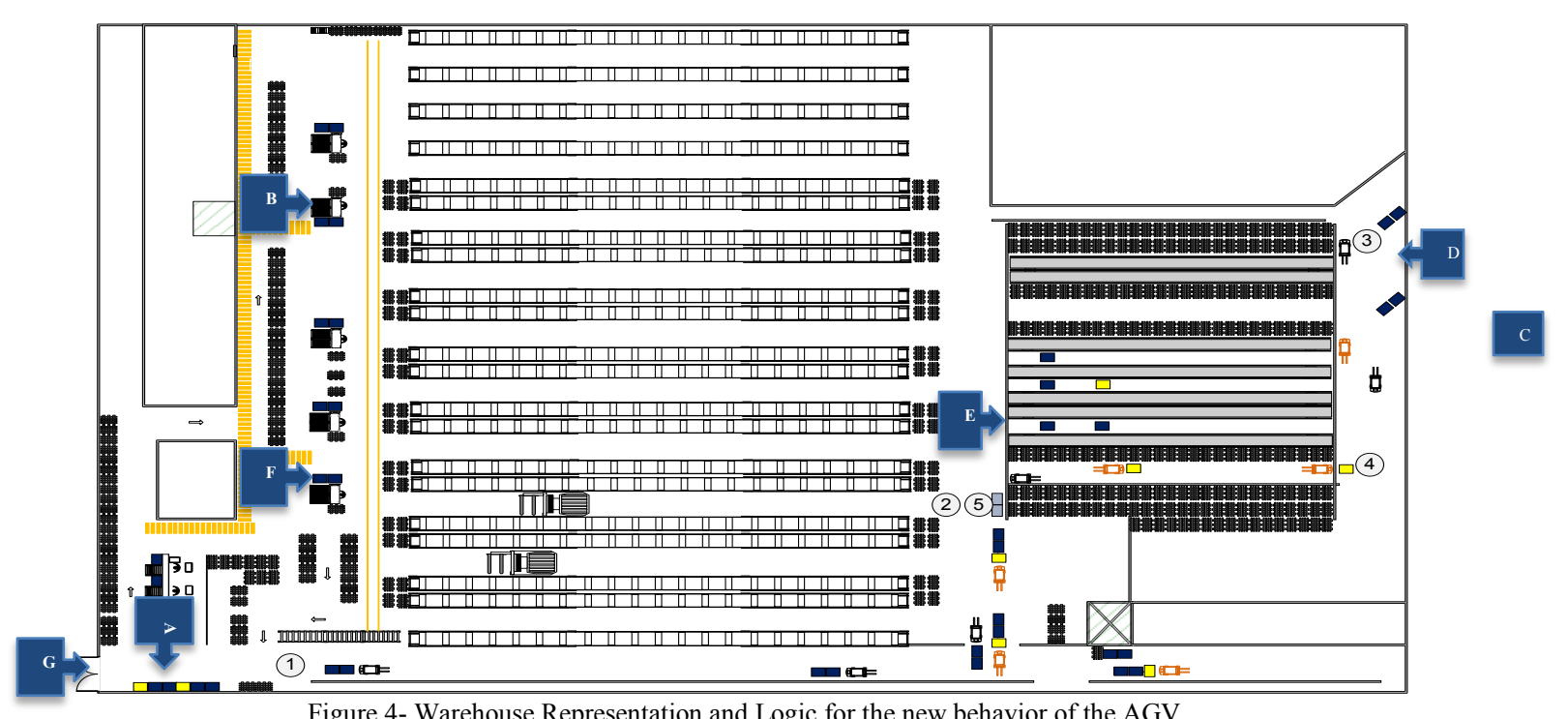

Figure 4- Warehouse Representation and Logic for the new behavior of the AGV

A- Buffer; B- Repacking station example; C - waste treatment facility; D-Unloading docks; E - Checking station; F- Bags side by side with repacking stations; $\mathrm{G}$ - Entrance to the final assembly area

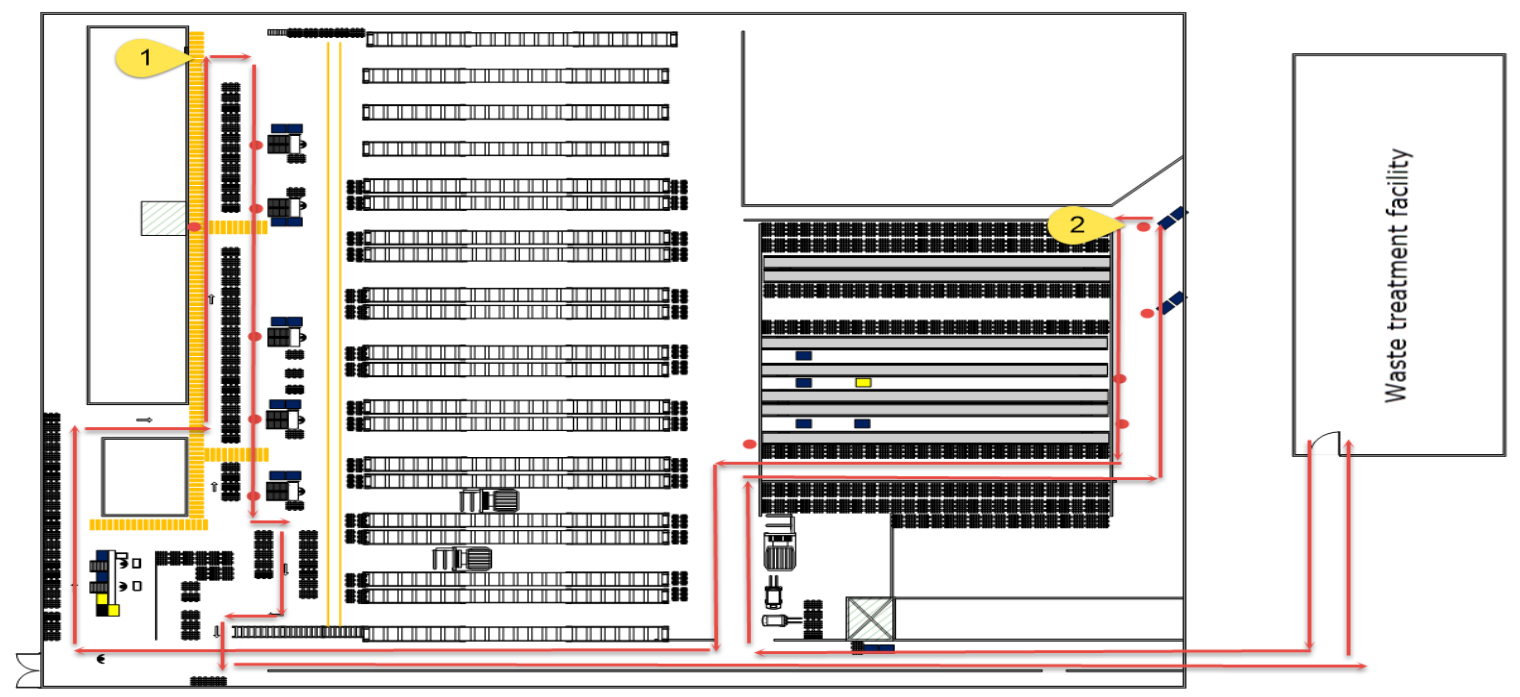

Figure 5- Drop-off, pick-up locations, and flow path for the AGV in the 2nd configuration

\section{Simulation of the AGV systems}

\section{1st configuration}

The first AGV configuration was similar to what was being done. Here we replaced the forklift for an $\mathrm{AGV}$, and improved the method of the pick-up of filled bags and the delivery of empty ones.

The differences are:

- Now the AGV can visit the buffer, checking stations, and unloading docks in the same trip. This was not the case with the forklift due to space restrictions. If the forklift picked-up filled bags from the buffer we couldn't pick more at the checking stations or unloading docks in the same trip, because that would require a U-turn at checking stations and there isn't enough space to do so with the bags clinched to the forklift.

- The AGV will now initiate a trip each time a filled bag is deposited on buffer or filled at the checking stations and unloading docks.

Figure 4 shows the new behavior for the AVG: at " 1 " the AGV collects two filled bags from the buffer, thus having space for one more. Because there is a movement order for a bag in the checking stations, then the AGV visits them. At " 2 " it temporarily deposits the bags gathered at the buffer, at " 3 " it makes a U-Turn, now possible thanks to the fact of not having bags clinched to the AGV. At " 4 " it picks a filled bag from the checking stations, and finally, at "5" it collects the previously deposited bags from the buffer and proceeds to the waste treatment facility. 


\section{$2^{\text {nd }}$ configuration}

This solution proposes a more radical change to the currently used system. Here we will replace two operators per shift by an AGV and collect the residues directly at the repacking stations. The AGV will behave in a similar fashion to that of a vehicle moving in closed circuit collecting and delivering bags along the route.

In Figure 5 the red dots indicates the pick-up and drop-off locations of bags. This solution assumes that the AGV has space to do U-turns with clinched bags at points 1 and 2. The AGV initiates a trip each time a bag is filled on one of the pick-up points, it can also visit every area during a movement, and can transport a maximum of 3 bags per trip

\section{E. Run of experiments}

All the models were run under 4 scenarios that represent 4 levels of production. The first scenario is for 127000 units, the average number produced during the period of the study. The $2^{\text {nd }}$ was for 178000 units, the max. number registered, and $3^{\text {rd }}$ and $4^{\text {th }}$ were $20 \%$ and $50 \%$ increases to this last scenario, meaning 213600 and 267000 units, respectively.

The simulations were run for 8 hours imitating a shift's activity, and were replicated 800 times. All the results were drawn for a $95 \%$ level of confidence.

\section{RESUlts ANALYSIS}

In this chapter we will assess the performance of each of the models in the metrics of: buffer size; operator travel distances; total travel distances, and lost output.

\section{A. Buffer size}

The plant, at the time of the study, had 6 square meters of space available to storage waste in the buffer. The employees responsible for the residues movement system empirically detected that this space was not enough, the buffer was constantly overcrowded and the actual space being used was more than $6 \mathrm{~m}^{2}$. The simulation proved this by demonstrating that at the current level of production, the installed system requires on average $11 \mathrm{~m}^{2}$ of space. The $1^{\text {st }}$ AGV configuration reduces the area needed by $2 \mathrm{~m}^{2}$ for each of the scenarios, but even for the current levels of production this configuration will need $9 \mathrm{~m}^{2}$, more than what's available. Lastly, the $2^{\text {nd }}$ configuration frees up that space, which can now be used to the vehicles better maneuvering (Figure 6).

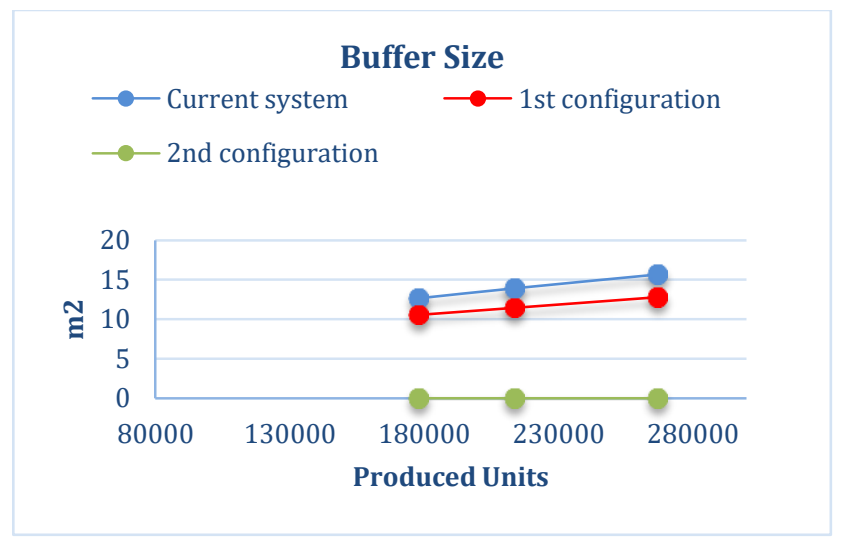

Figure 6- Buffer size for the current system and AGV configurations

\section{B. Distances travelled by operators}

Both current state and $1^{\text {st }}$ configuration have two operators moving bags by foot, therefore both solutions have a similar performance on this metric. However, leadership was not aware of the distances covered by these two operators, combined they walk around $20 \mathrm{~km}$ per shift, $15 \mathrm{~km}$ for one of the operators and 5 for the other. The one that covers $5 \mathrm{~km}$ /shift shares its capacity doing other activities beyond moving bags, the other, is allocated full-time to that task. The $2^{\text {nd }}$ configuration is again better on this metric because it doesn't require the work of the operator that currently walks, the enormous distance of, $15 \mathrm{~km}$ per shift (Figure 7).

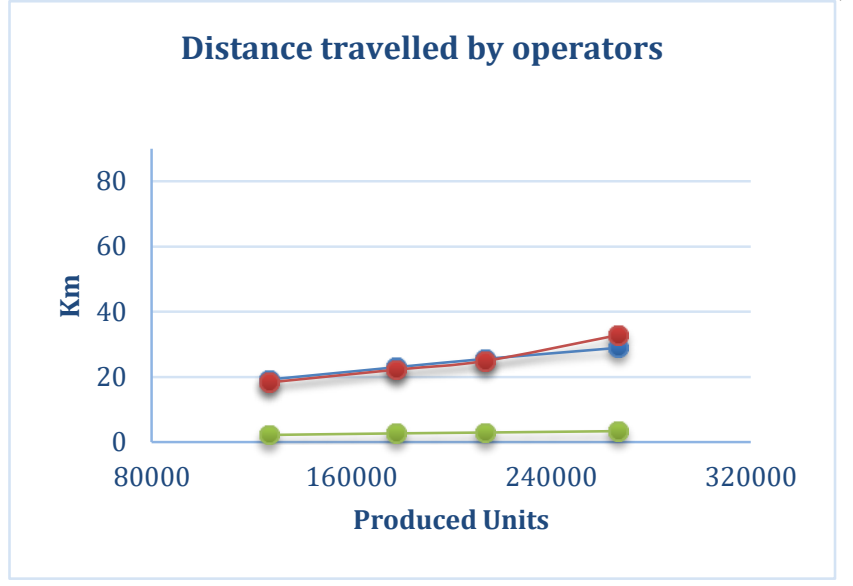

Figure 7- Distances travelled by the operators

\section{Total travelled distances}

Total travelled distances is the aggregation of the distances covered by the AGV or the forklift and those covered by the operators. The $1^{\text {st }}$ configuration has the highest value. In the $1^{\text {st }}$ configuration model, we established the rule that one bag waiting on the buffer is what it takes for a trip to be initiated, consequently the number of trips done by the AGV will increase, and thus the reason why the number of bags waiting on the buffer decreases.

Something interesting happens with second configuration, with the intensification of the waste generation no more trips are done. Even though the $2^{\text {nd }}$ configuration is not purely a closed circuit, in practice it behaves just like one. And so no more travels are done, what changes are the number of bags moved in each trip. As more waste is produced the greater will the ratio of bags transferred per trip be (Figure 8).

\section{Output Lost (Units)}

Those losses represent the difference between the bags filled and those that are moved to the treatment facility. Every time we have un-transported bags it means that the repacking stations had to stop its activity. Assembly lines will receive materials with a delay and at the end of a shift production plans will not be met. For each bag that is not transported we estimate a loss of 133 units of finished and semi-finished product. Here we can see (Figure 9) that for the current production levels no losses are foreseen for any of the systems, but the picture changes for the scenarios of 213600 and 267000 units produced. 


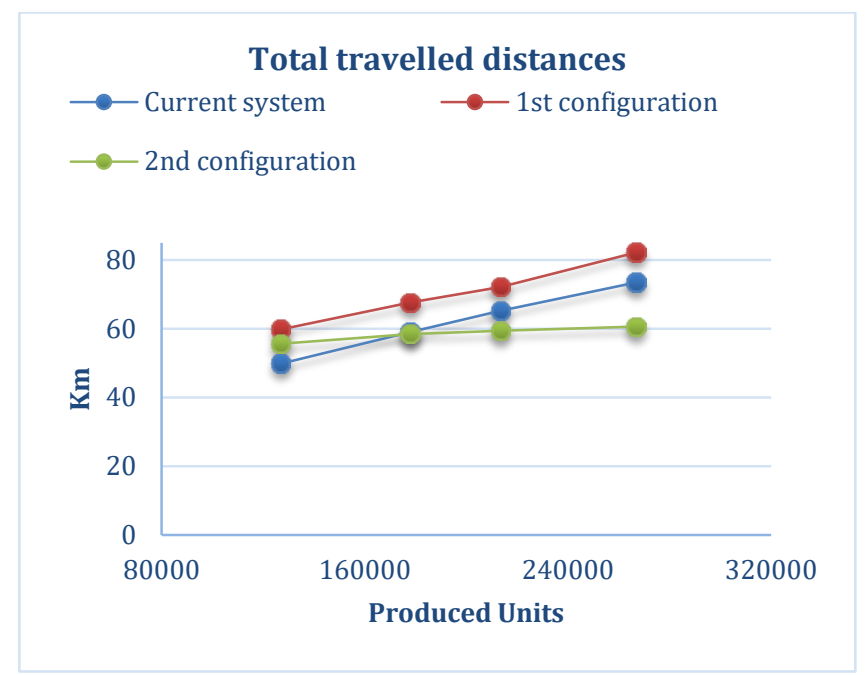

Figure 8- Total travelled distances (AGV/forklift +operators)

The reason why in the $2^{\text {nd }}$ configuration the loss of units rises exponentially after the 213600 units target is due to the fact that each time the AGV starts a trip the number of bags waiting to be transported along the path is systematically greater than 3. This does not happen in the other solutions because there is an operator that collects the bags from the repacking stations to the buffer, thus the workload of the AGV or the forklift is lower. We can still use the $2^{\text {nd }}$ configuration for this hypothetical production levels by increasing the No. of AGVs, instead of one we will need two.

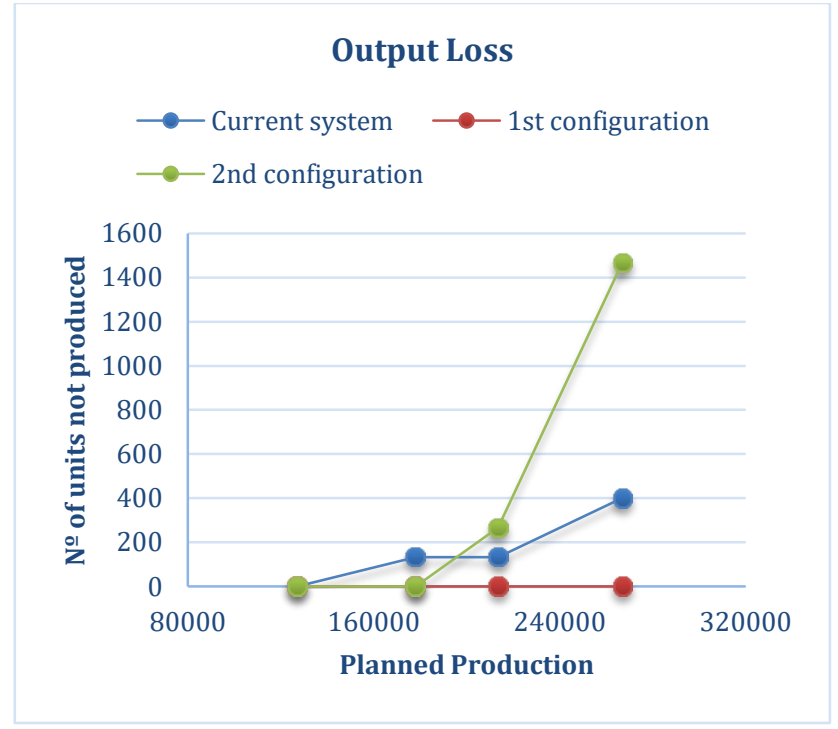

Figure 9- Output losses due to un-transported big filled bags

\section{CONCLUSIONS}

The AGV configurations presented throughout this work were both valid in terms of functionality and economics. The $1^{\text {st }}$ is an adaptation of the current system, that reduces the headcount of the process by one operator per shift, and decreases the space needed on the buffer by $2 \mathrm{~m}^{2}$, which by itself decreases the level of congestion on the intersection of the two flows, but in contrast, it rises the total travelled distances of the system, due to the increase on the number of trips. For this reason it's very difficult to assess if there is any gain on the fluidity of the system. This solution has a net present value of $90.576 €$ and payback time of three and half years. The $2^{\text {nd }}$ AGV configuration is better in buffer size, total travelled distances and it has enough capacity to deal with the current levels of production. It also has a net present value of $232.373 €$, and a payback time of less than two years. Those very good financial metrics come from the huge gain in headcount reduction. With this proposal we are reducing 2 operators per shift, 6 if we count that the plant operates in 3 shifts. In general terms, this work proved the validity of the $\mathrm{AGVs}$ as a solution. Financially, AGV technology proves itself to be very lucrative, especially in operations that spread out through more than one shift.

\section{REFERENCES}

[1] Gotting, H. H. (2000). Automation and Steering of Vehicles in ports. Port Technology International (10).

[2] Ganesharajah, T., Hall, N. G., \& Sriskandarajah, C. (1998). Design and operational issues in AGV-served manufacturing systems. Annals of OR, 76, 109-154. doi: 10.1023/a:1018936219150

[3] Vis, I. F. A. (2006). Survey of research in the design and control of automated guided vehicle systems. European Journal of Operational Research, 170(3), 677-709. doi: 10.1016/j.ejor.2005.09.020

[4] Gaskins, R. J., \& Tanchoco, J. M. A. (1987). Flow Path Design For Automated Guided Vehicle Systems. International Journal of Production Research, 25(5), 667676. doi:10.1080/00207548708919869

[5] Goetz, W. G., \& Egbelu, P. J. (1990). Guide path design and location of load pick-up drop-off points for an automated guided vehicle system. International Journal of Production Research, 28(5), 927-941. doi:10.1080/00207549008942764

[6] Banks, J. (1998). Principles of Simulation: WileyInterscience.

[7] Castleberry, G. A. (1991). Automated Guided Vehicle Handbook: Handbook for the Selection of Automated Guided Vehicle Systems: AGV Decisions Inc.,U.S.

[8] Dai, J. B., \& Lee, N. K. S. (2012). Economic feasibility analysis of flexible material handling systems: A case study in the apparel industry. International Journal of Production Economics, 136(1), 28-36. doi:10.1016/j.ijpe.2011.09.006

[9] Dias, L.S.; Pereira, G.B.; Vik, P. and Oliveira, J. (2011). Discrete Simulation Tools Ranking - a Commercial Software Packages comparison based on popularity. ISC 2011 - 9th Industrial Simulation Conference, June 6-8, 2011, Venice, Italy, pp. 5-11.

[10] Hammond, L. (1986). AGVs at work. United Kingdom: IFS Publications Ltd.

[11] Mahadevan, B., \& Narendran, T. T. (1993). Estimation Of Number Of Agvs For An Fms - An Analytical Model. Int. J. of Production Research, 31(7), 16551670. doi:10.1080/00207549308956815

[12] Sargent, R. G. (2011, 11-14 Dec. 2011). Verification and validation of simulation models. Paper presented at the Simulation Conference (WSC), Proceedings of the 2011 WSC. 